\title{
Understanding as a Concept in Education: Conceptions and Alternative Interpretations
}

\author{
Prof. Samson Gunga \\ School of Education, University of Nairobi \\ Prof. Henry Etende Embeywa \\ School of Education, Mount Kenya University \\ embeywa@gmail.com \\ Dr. Wycliffe Amukowa \\ School of Education, Mount Kenya University
}

Doi:10.5901/jesr.2014.v4n1p339

\begin{abstract}
Education has largely been conceptualized as transmission and acquisition of knowledge, skills, attitudes and values so as to facilitate desirable behavior. This conceptualization presupposes knowledge, skills, attitudes and values as sufficient conditions for desirable behavior; however this paper argues that these are necessary but not sufficient without Understanding. What understanding is or is not, and how it is to be justified as an educational condition demands explicit attention.
\end{abstract}

\section{Introduction}

Peters (1967) argued that to lay claim to education, first the learner must possess the capability to understand what he is being taught. Second, the process must be done in a manner that is morally acceptable and third, it must be a conscious effort to bring about a positive change in the state of the mind of the recipient which must be directed at achieving a desirable goal. Boyd and King (1977), consider education to be the training and instruction of the young for the business of life. Gwanfogbe (2006) supports this definition of education as given by Boyd and King (1977) and argues that this definition is appropriate because since the beginning of human civilization each human society has been interested in training the future generation to improve on their social, economic, cultural and political life of their society.

Mohanan (http://www.cdtl.nus.edu.sg/publications/educated/intro.htm) disagrees with the definition of education as training and observes that education is not the same as training, even though training may be one of its ingredients. He argues that for instance, a person who has been taught to repair refrigerators, drive an automobile, or play basketball can be said to have received training, but such training per se does not constitute education. Similarly, even though learning is a necessary ingredient of education, not all forms of learning lead to education. Monkeys, birds, and rats can learn from experience, and they can even be trained, but it cannot be said that they can be educated. Mohanan(ibid) then defines education as the process of actualizing what is unique to the human mental potential. Education enhances the human mental capability because it is a preparation for future life, and a good way of preparing individuals for future life is to enhance their mental capability so that they can cope with the challenges of life more effectively.

According to Balogun (2008), in its etymological derivation, education comes from the Latin word "educere" meaning to "lead out" or "to bring out." Balogun (2008) argues that this definition is sterile as another school of thought has denied that education comes from "educere", to "lead out", but rather from "educare" which means to "form" or "train". This way Balogun (2008) maintains that education refers to the act of developing knowledge, skills or character of a child. It may also be defined as the act of bringing up, rearing, guiding or directing a child. The 1828 edition of Noah Webster's An American Dictionary of the English Language http://modernedfailedus.blogspot.com /2005/12/times-havechanged.html) presents the definition of Education as the bringing up, as of a child; instruction; formation of manners. However, Omona (1998) argues that education is not only tied to children because adults or persons beyond the connotation of a child continue to be nurtured through education. Indeed, to conceptualize education with focus on a child pays no respect to the present day reality of continuing and adult education.

With the coming of industrialism and increase in demand for knowledge and skills, education became increasingly 
associated with schooling and with sort of training and instruction that went on in special schools. According to Hirst (1990), this has culminated in the development of compulsory schooling for all, and may well have brought about such a conceptual tightening up that education is used with a connotation of knowledge and understanding. Within this purview, UNESCO (19995) defines education as comprising organized and sustained communication designed to bring about learning. This definition associates education with schooling or literacy. Indeed in its part of definition of education, the 1983 edition of Webster's New Twentieth Century Dictionary Unabridged Edition, provides that it is the process of 1) training and developing the knowledge, skill, mind, character, etc. especially by formal schooling; teaching; training. 2) Knowledge, ability, etc. thus developed, 3) formal schooling.

In the light of the above definitions, it appears that Education has largely been conceptualized as transmission and acquisition of knowledge, skills, attitudes and values so as to facilitate desirable behavior. This conceptualization presupposes knowledge, skills, attitudes and values as sufficient conditions for desirable behavior; however this paper argues that these are necessary but not sufficient without Understanding. What understanding is or is not, and how it is to be justified as an educational condition demands explicit attention.

\section{The Concept of Understanding}

Views that underscore the importance of understanding, as a human phenomenon involved in the attainment of knowledge, are various: Paulo Freire holds that understanding is a fundamental part of humanness. It is due to it that man is distinguished as capable of being in the world and with the world. This is because while brutes are guided by habit, man has the potential to step back from reality and to make it, based on his visions of what is right. John Locke, in his contribution on the idea of understanding maintains that understanding helps man to direct his thought in search of knowledge. It is Understanding that sets man above the rest of sensible beings, and gives him dominion over them.

Immanuel Kant is even more assertive. He believes that knowledge is not possible without understanding. To him, it is understanding that unifies all the diverse human intuitions to bring them under concepts. Gilbert Ryle, for his part, says that understanding is a degree of competence in performance that enables one to apply theory. That is, a person with understanding like one with practical ability can get the right results for he has the ability, to see what needs to be done in various circumstances. Ryle further asserts that, one with understanding has an orientation upon which he can accomplish proven tasks, related to knowledge acquisition. Martin observes that the test for understanding lies in performance, and she advances the following argument to support her claim: that to understand an argument, for example, is to put it in one's own words, invent appropriate illustrations, stand up to cross questioning, draw further conclusions and so on. She further believes that, understanding is linked both to intrinsic and extrinsic difficulties, which are related to the object of understanding. Thus, to understand is to overcome such difficulties by way of reasoning namely, analysis, explanation and interpretation. Therefore, no single performance determines whether a person understands an argument. Although it may not be specified how many, or what tests must be met in gauging one's understanding, a finite set of well defined tests is enough in any given case. She sums up the argument by saying that, understanding is seen to involve the process of changing an unfamiliar process into a familiar one, by rediscovery using objective standard procedures.

Ziff in his contribution offers an analysis of understanding. He believes that understanding is some sort of analytic process, related to the complexity of the object concerned. The connection between knowledge and understanding is also treated by John Dewey. He equates understanding with the knowledge of the meaning of a thing in that; something is understood once its meaning is discerned.

\section{Analysis of the Concept of Understanding}

If the notion of understanding is to carry significant magnitude in educational theory and practice, it is essential that it be delineated with some precision. Such endeavour uncovers the meaning of the issues about the desirability of understanding, or of educational efforts aimed at improving students' understanding.

Distinct episodes of understanding may be said to have certain features in common that distinguish them as instances of understanding. Thus the concept of understanding may denote what it is about a variety of abilities and achievements that make them instances of understanding. Therefore, the generality that the concept of understanding has presupposes something that is common about all understanding episodes.

Ziff believes that understanding is essentially an analytic process, whose difficulty27 relates to the structural complexity of the object concerned. What things that can be understood have in common is structure. Only that which is 
composite, complex and thus capable of analysis can be said to be understood. According to Ziff, difficulty in understanding results from internal or syntactic intricacy of the object concerned. This is because the more complex a structure is, the more it is difficult to understand. So, to increase the complexity of the structure of something is tantamount to increasing the intrinsic difficulty of understanding it.

Ziff in his treatise, does not state precisely the form of processing that understanding refers to, however, Rosenberg2 29 offering a critique of Ziff's point of view observes that difficulty in understanding is not always related to the complexity of the object concerned. This is due to the fact that an object may be difficult to understand not only because of its particular complexity, but also because of its too great simplicity. The difficulty may stem from its exceptional aspect or equally from its excessively ordinary, mundane and peculiar character. Rosenberg also believes that there is a common property of all objects of understanding, which he does not indicate. Nevertheless, Rosenberg discusses elaborately the relationship between the said property and the concept of understanding. For discussion purposes, let the property proposed by Rosenberg be named in this paper as "Y". In Rosenberg's view, to increase $Y$ is to increase difficulty in understanding and to decrease $Y$ is to decrease such difficulty. This is to say that as $Y$ varies (is varied), difficulty in understanding varies directly, so to speak - thus difficulty in understanding is function of Y. Rosenberg claims that anything that is amenable to understanding has a certain objective property which could be discerned. This is contrary to views held by Merleau - ponty (a) who sees subjectivity in our ways of understanding when he claims that 'we find in texts only what we put into them'.

To critically discuss Rosenberg's conception, consider Bauman's observation:

One can think seriously of an understanding as a planned or deliberate activity only in as far as resistance has been encountered, as significance* of the object is not given matter-of-factly...

According to Bauman, open to understanding are those objects whose significance can in principle be discerned, hence what objects of understanding have in common is significance. However, the notion of variation of $Y$ causes variation of difficulty in understanding, difficulty arising from lack of significance emanates from the context in which a thing is rendered significant. Ways by which a thing is significant are discussed in the next section; they are analysis, explanation and interpretation. They emphasize that, the concept of understanding refers to those ways and means by which the significance of a thing is discovered. To render an object significant is to fit it into a conceptual framework that makes it intelligible. The processes that actually generate understanding of a domain are similar to the processes utilized in gaining knowledge. Thus understanding and knowledge are closely related as shown in the next section.

\section{Understanding and Knowledge}

Epistemological theory of understanding states that one who understands something possesses implicit knowledge about the meaning of such a thing. In line with this theory, a question could be raised thus: What is the potency of such knowledge to which understanding relate? The kinds of understanding that one achieves in a study can have important consequences, such as the ability to transfer knowledge to relevant tasks and the efficiency by which additional knowledge is acquired.

In the ensuing discussion, a number of authors contend that there is warranted relationship between knowledge and understanding. R. S. Downie says that, one who knows "must understand what he knows in the sense of being able to see some of the implications of it, something of what it 'amounts' to. Implicit in Downie's contention is the distinction between understanding and knowledge. Louis Reid concurs with Downie's contention by asserting further that understanding and knowledge are only distinguisable conceptually though inseparable existentially. According to D. W. Hamlyn, it is a fallacy to claim knowledge without understanding.

\section{... Knowledge presupposes... understanding. It is possible ... for someone to think that he knows something but in fact not know it simply because he has no real understanding of what is involved.}

Hamlyn holds that all knowledge presupposes that the person who knows has relavant kinds of understanding. Such a person has certain ideas which form the basis of formulating and expressing his knowledge. One who understands an "X", for examle, not only knows the formal defining conditions of X, but also what counts as an X. It is in this sense that Dummet claims that to understand something is to know its meaning, that is, to know its defining conditions and the contextual setting upon which it could be rendered intelligible. He thus believes that knowledge of the meaning of an expression, for example, consists of the ability to state the rules, logical or otherwise in accordance to 
which the expression is used. Dewey in a similar contribution supports the idea that understanding is the knowledge of meaning:

To grasp a meaning, to understand, to identify a thing in a situation in which it is important are... equivalent terms .... to say that you do not understand it and that it has no meaning (in ones one situation) are equivalent.

In relating knowledge and understanding, Dewey writes further:

"All knowledge... aim to grasp the meaning of objects and events, and this process always consists of taking them out of their apparent brute isolation as events, and finds them to be parts of some larger whole suggested by them, which in turn accounts for, explains, interprets them; i.e., renders them significant".37

Dewey stresses that understanding is a function of the extent to which adequate meanings are generated in a particular context. Rotenstreich advances a similar argument:

"In so far as there is understanding, ther are meanings to which it refers, and in so far as there are meanings, there is... understanding that refers to them."

Rotenstreich puts it that a thing is understood in the context that reveals its meaning - that which renders it significant. The major question that needs to be tackled now is: What are the ways by which significance is revealed?

According to Martin, understanding can be achieved in either of two ways:

"... by looking around or beyond it... or by looking into it, in one sense of "analysis" and in the one sense of "placing a thing in some context of framework", then we can say that to understand something, $X$, one must either analyse X or place $X$ in some context of framework."

Martin believes that powers of understanding remain mere possibilities until they are called into action by the actual or plossible relations, which subsist within or among objects. It is the contention of this study that Martin's observation adequately explains the connection between understanding and discovery of significance. A thing is never understood per se, but rather, it is understood under some description. When parts of a thing are singled out for attention, different sorts of relationships can be seen. In such cases, when one talks of understanding, one often refers to the grasp of the contribution of various parts to the whole. One could also single out for attention, connections or relations which take various forms such as logical, causal and temporal.

Sometimes impediments to understanding are due to intrinsic difficulty, that is, internal complexity in which case analysis yields understanding. Difficulty in understanding may also arise from blurriness, vagueness or indistinctiveness. In such cases analysis involves systematically building up a network of connections and relations. This includes, elucidation through tracing of boundaries and articulating a criterion of inclusion, exclusion and application that makes precise what is to be understood. In this context, an object of understanding is treated as composite and parts or aspects of it are related in order to see their contribution to the whole. Understanding here, involves redescription of the parts in order to see how they fit in a pattern with already known entities, or with one another.

On another level, difficulty in understanding may result from extrinsic problems or from contextual isolation. There could be anomaly or failure of the object of understanding to cohere with readily available unitary context. First, if impediment is due to utter simplicity, then understanding involves interpretation which entails finding context for what is otherwise anomalous. In such cases then, a given thing bears all sorts of relationships to things outside it the consideration of which could yield understanding in context. Secondly, impediments to understanding may also be due to incoherence between an object and its surroundings, that is, things upon which it can be explained.

According to Rosenberg:

"The search for explanations is the search for increasingly broad integrated and coherent inferential systems, constitutive of families of concepts in terms of which, the continuing flux of experience can be evermore adequately described."

Rosenberg believes that there is analytic relationship between explanation and understanding, and that one understands only that which one is able to explain and vice versa. Generally, we often confess our lack of understanding by seeking for an explanation of what puzzles us. Although being given an explanation is no guarantee that one then understands, we acknowledge the fact that possession of ability to explain something is indicative of the understanding of 
it. So then,when one who has logical knowledge of explanation is able to explain ' $X$ ' then one understands ' $X$ '.

Embeywa (1990) in his unpublished PhD Thesis identifies three major processes in understanding:

1. Visualization- which involves the formation of mental representations

2. Manipulation- which involves application of rules of inference to assess the mental representations, and

3. Explanation-Perception- the final act of perception of the underlying causal mechanisms.

In the above context, one would argue that understanding consists in three levels. Thus, without visualization it would be difficult to manipulate mental pictures; and without manipulation, there would be no basis for explanationperception. One can picture a situation in the mind without understanding the causal mechanisms involved. It is also possible that one can picture, manipulate mental pictures but fail to arrive at an accurate explanation- perception. However, no explanation- perception can occur in the absence of both visualization and manipulation. It is prudent therefore to argue that understanding has levels of gradual sophistication.

Embeywa (1990) further argues that a learner can only understand if they have the capacity to form appropriate and relevant pictorial as well as mechanistic mental representations in the context of the situation. The mental representations would form the basis of mental manipulation, reasoning and inference generation. The highest level of understanding would culminate to explanation- perception and that all these processes would depend on as well as enhance knowledge, skills, attitudes and values.

A synthesis of the various views expressed above shows that understanding and knowledge are existentially indistinct, and the apparent distinctions that arise are only conceptual. The justifications for various beliefs upon which knowledge rests, have their basis on the understanding of the meaning and truth values of such beliefs. Justification requires the temporary suspension of belief in order to assess the coherence of the evidence for the belief. A belief is justified when it is confirmed by what is evident, which gives it explanatory power. When one claims to know, one must admit the pertinence of the test of understanding challenges as follows: How do you know? What warrants you in believing? What do you mean? among other questions; all of which highlight vitality of the analysis, interpretation and explanation of one's position in regard to one's knowledge. Thus knowledge is founded on understanding where its validity is grounded, while understanding is anchored on knowledge as the object of intentionality.

The discussion put forward reveals that understanding is a generalized notion. It is concerned with conceptual organisations that reveal the significance of that which is to be understood. To understand something is to place it in a context of thought or action, in which it can significantly be said to have meaning. This connotes that in order to understand, one has to be acquainted with universal entities that constitute the meaning of an idea. Understanding is then a function of the extent to which adequate meanings are generated, in the context that reveals the meaning of the object of understanding. It is in this regard that, understanding is considered as the possession of implicit knowledge that relates to the meaning of an entity.

It is this papers' view that understanding is a process that encompasses mental picturing, complex mental manipulations in the light of inferential rules, and a final act of perception of linkages and interconnectivity between parts constituting a situation. Knowledge, skills, attitudes and values are therefore necessary but not sufficient conditions for Education.

\section{Understanding, Knowledge and Education}

It has been argued in this paper that a person can have knowledge without understanding but cannot have understanding without knowledge. This way understanding becomes a key indicator of ones' knowledge. Understanding therefore becomes a sufficient concept in the transmission of knowledge.

Education conceptualized in the light of transmission of knowledge founds itself on the tenets of understanding. Embeywa (1990) discusses the tenets of understanding as:

Visualization- which involves the formation of mental representations (...)Manipulation- which involves application of rules of inference to assess the mental representations, and(...)Explanation-Perception- the final act of perception of the underlying causal mechanisms (Embeywa,1990:25-40).

Embeywa (1990) elaborates that there are three types of Visualization:

(i) VP: Pictorial Visualization that involves schematization of well defined inputs into a pictured situation.

(ii) VM: Mechanistic Visualization that involves an abstract awareness (spontaneous or generative) of causal mechanisms or dynamic relationships underlying a physical process which may include abstract imagery.

(iii) VF: Formal Visualization that involves a mapping of physical situation into a mathematical situation.

Manipulation involves several levels of constructive sophistication: 
(i) Assessment of mental models

(ii) Assimilation through creative manipulation of mental models

(iii) Abstractions in search of symmetry through logical, causal or analogical reasoning.

The ontological unification of percepts and concepts into valid or acceptable explanation is what constitutes Explanation-Perception. Here, the links between the elements of mental representations become clear by underpinning the relevant causal or probabilistic or statistical mechanisms that explain the phenomenon under consideration.

One can therefore be said to have attained full understanding only if this final act of perception is achieved.

\section{Conclusion}

Understanding has been presented as a composite concept. It is our view that understanding has the following qualities:

(i) Understanding is existentially knowledge driven.

(ii) Understanding is an iterative and hierarchical process actualized by three mental faculties: viz. The Representational faculty, the Manipulative faculty and the Perceptual faculty.

(iii) Understanding is an analytical process linked to the character, significance and context of objects.

(iv) Understanding is inseparable from explanatory competence.

(v) Understanding is a generative notion about meaning and context of explanation.

In the above regard, knowledge, skills, attitudes and values are necessary but not sufficient conditions for Education without understanding.

\section{References}

Bauman, Zygmunt (1978). Hermaneutics and Social Sciences: Approaches to Understanding. London: Hutchinson \& Co., Ltd. Dewey, John (1910). How to Think. Boston: B. C. Health \& Co. Publishers.

Downie R. S. (1974). Education and Personal Relationship. London: Methuen \& Co. Ltd.

Dummet, Michael (1983). "The philosophical basis for intuitionistic logic", in Paul Benacerraf et. al., (eds), Philosophy of Mathematics: Selected readings. Cambridge: Cambridge University Press.

Embeywa,E.Henry (1990) Students' Construction and Assessment of Scientific Explanation. Ph.D Thesis. University of London.

Freire, Paul (1985). The Politics of Education: Culture, Power and Liberation trans. by Donaldo Macedo. Massachussetts, Bergain \& Garvey Publishers.

Hamlyn, D. W. (1970). The Theory of Knowledge. London: The Macmillan Press, Ltd., 1970).

Kant, Immanuel (1976). Kant's Critique of Pure Reason: A Commentary for Students by T. E. Wilkerson. Oxford, Clarrendon Press.

Locke, John (1973). "Human Understanding and Improvement of Knowledge," in John De Lucca (ed), Reasons and Experience. San Francisco, Freeman.

Martin, Jane R. (1970) Explaining, Understanding and Teaching. New York: McGraw-Hill Book Co.

Martin, Jane R. (1970). Explaining, Understanding and Teaching. New York: McGraw-Hill Book Co.

Merleau - Ponty, M. (1962) Phenomenology of Perception Trans. By Colin Smith London: Routledge \& Kegan Paul.

Reid, Louis (1986). Ways of Understanding and Education. London: Heinmanann Educational Books.

Rosenberg, Jay F. (1981) Quoted by Herman parret et. al., "Introduction", in Herman parret and Jacques Boveresse (eds) Meaning and Understanding. New York: Walter De Gruyter.

Rosenberg, Joy F. (1974) Linguistic Representation (Boston: D. Reidel Publishing Co.

Rotenstreich, Nathan (1977). Theory and Practice: An essary in Human Intentionalities. The Hague: Martinus Nijhoff.

Ryle, Gilbert (1940). Concept of Mind. New York: Barnes \& Noble Books.

Ziff, Paul (1972). Understanding understanding (London: Cornell University Press. 